\title{
IMOBILIZAÇÃO DA ENZIMA LIPASE COMERCIAL EM XEROGEL OBTIDO PELA TÉCNICA SOL-GEL UTILIZANDO LÍQUIDO IÔNICO COMO ADITIVO.
}

\author{
K. L .D .LEVANDOSKI ${ }^{1}$, A. M. M. FICANHA ${ }^{1}$, N. N. NYARI ${ }^{1}$, A. ANTUNES ${ }^{1}$, E. \\ MORESCO$^{1}$, R. ZAMADEI ${ }^{1}$, M. H. BOPSIN ${ }^{1}$, A. PAULAZZI ${ }^{1}$ e M. L. MIGNONI ${ }^{1}$ \\ ${ }^{1}$ Universidade Regional Integrada do Alto Uruguai e das Missões, Departamento de \\ Engenharia de Alimentos \\ E-mail para contato: katarinelevandoski@gmail.com
}

\begin{abstract}
RESUMO - O principal objetivo da imobilização de enzimas é obter um biocatalisador com atividade e estabilidade que não sejam afetadas ao final de um processo, em comparação a sua forma livre, além de facilitar sua reutilização e consequentemente trona-se um processo viável. Dentre as diferentes formas de imobilização, a técnica sol-gel destaca-se devido a possibilidade de imobilização in situ, controle da temperatura e $\mathrm{pH}$ na polimerização do suporte, além de permitir o uso de aditivos que atuam na proteção da enzima, aumentando a atividade e a estabilidade. Neste contexto, o objetivo do presente trabalho foi imobilizar a lipase comercial de Candida antarctica (Cal B) pela técnica sol-gel e utilizar liquido iônico como aditivo para a obtenção de uma melhor atividade de esterificação na síntese do oleato de etila. Utilizou-se diferentes concentrações do líquido iônico (LI) brometo de 1-octil- 3metil imidazólio e avaliou-se o comportamento da atividade de esterificação. As maiores atividades de esterificação foram nas menores concentrações de líquido iônico, e a maior foi em $1 \%$, na qual apresentou atividade de $520 \mathrm{U}$ e rendimento de $620 \%$.
\end{abstract}

\section{INTRODUÇÃO}

Melhorar a qualidade de vida é um dos princípios da sustentabilidade, contudo, o maior desafio dá-se na continuidade dos avanços em pesquisas, diminuindo principalmente os danos ao meio ambiente. A aplicação de enzimas como catalisadores exemplifica muito bem os avanços na área, que apesar das limitações na aplicação industrial, vem sendo cada vez mais estimulada, pois as vantagens do ponto de vista ambiental são bem maiores do que a dificuldade encontrada na biotransformação utilizando enzimas livres ou imobilizadas para catalisar as diversas reações de interesse industrial (Souza et al., 2013).

As lipases destacam-se entre as principais enzimas usadas em biocatálise, pois apresentam capacidade de catalisar reações tanto em meio aquoso como em meio orgânico, onde o teor de água é limitado. Além disso, o elevado potencial de aplicação das lipases é justificado pela sua capacidade de utilização de uma ampla gama de substratos, sua estabilidade frente à temperatura, $\mathrm{pH}$ e solventes orgânicos e sua quimio-regio e enantiosseletividade. O potencial de aplicações industriais das lipases abrange, além da indústria de alimentos, como aditivos (modificação de aromas), a química fina (síntese de 
ésteres), detergentes (hidrólise de gorduras), tratamento de efluentes (decomposição e remoção de substâncias oleosas), couro (remoção de lipídios das peles dos animais), farmacêutica e a área médica (remédios, digestivos e enzimas para diagnósticos) (Kapoor et al., 2012).

A imobilização de enzimas em suportes sólidos tem sido amplamente empregada para proteger e obter estabilidade da amostra enzimática durante o processo catalisado pela mesma. A imobilização tem como principal característica o uso de alguma estrutura física de confinamento, forçando a enzima a permanecer em uma região particular de um biorreator e apresentando vantagens como a possibilidade de uso em processos contínuos, o aumento da estabilidade da enzima, redução do volume de reação, a regeneração e o reaproveitamento da enzima, e, consequentemente, a redução dos custos (Souza, 2012).

Diferentes técnicas de imobilização são utilizadas para conservar a natureza catalítica do biocatalisador, dentre elas, destaca-se o método sol-gel baseado em métodos químicos e físicos, que consiste em proteger às biomoléculas em um volume definido e criar um único compartimento, representando um microambiente separado do ambiente externo (Kato et al., 2011). A imobilização da enzima no interior das matrizes produzidas pelo processo sol-gel é uma técnica vantajosa, pois reserva a atividade enzimática e evita a sua lixiviação (Alfaya,et al, 2002).

O uso de aditivos no processo de imobilização sol-gel é relatado na literatura como agentes que influenciam positivamente o aumento da atividade e da estabilidade de enzimas imobilizadas (Hara et al., 2010). Essa influência está diretamente associada à proteção da enzima contra a inativação durante a etapa de encapsulamento, à retenção da camada de água ao redor do biocatalisador e aos efeitos dispersantes das moléculas da enzima. Dentre os principais aditivos utilizados na imobilização de enzimas, destacam-se a caseína, gelatina, albumina, álcool polivinílico, polietilenoglicol e, recentemente, o uso de líquidos iônicos, que são sais fundidos a baixas temperaturas, e que, apesar de serem documentados principalmente para substituir solventes orgânicos voláteis, apresentam enorme potencial em aplicações podendo como aditivos durante o processo de encapsulamento sol-gel de enzimas (Souza 2012; Souza et al., 2013).

Quando relaciona-se à utilização de LI em meios reacionais utilizando catalisadores, alguns estudos demonstraram que uma variedade de enzimas tem a capacidade de realizar atividades catalíticas iguais ou até mesmo superiores aos solventes convencionais. Além de poder fornecer um meio que proporcione a estabilização da enzima, eles facilitam a remoção de substâncias voláteis por possuir uma pressão de vapor inerentemente baixa (Peters et al., 2007).

Neste sentido o objetivo do trabalho foi estudar diferentes concentrações de líquidos iônicos na imobilização da lipase de Candida antarctica B (Cal B) em xerogel obtido pela técnica de sol-gel.

\section{METODOLOGIA}

\subsection{Imobilização da enzima lipase pela técnica de sol-gel}


A lipase de (Cal B) foi imobilizada de acordo com Ficanha (2014). Cinco mL de tetraetilortosilicato (TEOS) foram dissolvidos em $5 \mathrm{~mL}$ de álcool etílico absoluto, após, foram adicionadas 3 gotas de catalisador ( $\mathrm{HBr}$ ) e 1,6 mL água destilada em uma proporção molar de TEOS:H2O (1:4). A mistura ficou sob agitação por 90 minutos, $40{ }^{\circ} \mathrm{C}, 180 \mathrm{rpm}$. Em seguida, foram adicionados $1 \mathrm{~mL}$ de solução enzimática, e líquido iônico brometo de 1-octil 3 metil imidazólio como aditivo (em diferentes concentrações). Após, foram adicionados $1,75 \mathrm{~mL}$ da solução hidrolisante $(0,25 \mathrm{~mL}$ de hidróxido de amônia dissolvido em $1,5 \mathrm{~mL}$ de etanol). A mistura foi mantida em condições estáticas por 24 horas para completar a condensação química. Após este período, a enzima imobilizada (derivado) foi condicionada em dessecador sob vácuo por mais 24 horas para a completa secagem. Após a secagem, o suporte foi armazenado para os posteriores testes.

\subsection{Determinação da atividade de esterificação}

A atividade de esterificação da lipase imobilizada foi determinada pela capacidade de síntese do oleato de etila realizada através da reação do ácido oleico e etanol (razão molar 1:1). Esta reação foi iniciada pela adição da enzima imobilizada $(0,1 \mathrm{~g}$ de suporte) ao meio reacional e a reação foi conduzida a $40{ }^{\circ} \mathrm{C}, 160 \mathrm{rpm}, 40 \mathrm{~min}$. A quantidade de ácido consumido foi determinada por titulação com NaOH 0,05 M até pH 11 (Ferraz et al., 2012). Os ensaios dos brancos das amostras continham $500 \mu \mathrm{L}$ da mistura padrão e $15 \mathrm{~mL}$ da solução de acetona-etanol. Uma unidade de atividade enzimática foi definida como a quantidade de enzima que consome $1 \mu \mathrm{mol}$ de ácido graxo por minuto, calculada pela Equação 1:

$$
A E=\frac{\left(V_{b}-V_{a}\right) \times M \times 1000 \times V_{f}}{t \times m \times V_{c}}
$$

Onde: AE: Atividade de esterificação (U/g); Va: Volume de $\mathrm{NaOH}$ gasto na titulação da amostra retirada após $40 \mathrm{~min}(\mathrm{~mL})$; $\mathrm{Vb}$ : Volume de $\mathrm{NaOH}$ gasto na titulação da amostra do branco (mL); M: Molaridade da solução de $\mathrm{NaOH}$; Vf: Volume final de meio reacional $(\mathrm{mL})$; t: Tempo (min); m: Massa da solução enzimática ou do suporte utilizado (g); Vc: Volume da alíquota do meio reacional retirada para titulação $(\mathrm{mL})$.

\subsection{Determinação do rendimento da imobilização}

O rendimento do derivado imobilizado foi calculado a partir da Equação 2:

$$
R(\%)=\frac{A T}{A A} x 100
$$

Onde: AT: Atividade de esterificação total do xerogel imobilizado; AA: Atividade de esterificação total presente na massa de enzima livre adicionada na imobilização.

\section{RESULTADOS E DISCUSSÕES}


A Tabela 1 apresenta os resultados da atividade de esterificação obtidos após a imobilização em xerogel com e sem a presença da lipase de Candida antarctica B (CAL B) e do líquido iônico.

\begin{tabular}{ccc}
\hline Xerogel & Atividade \pm desvio padrão (U/g) & Rendimento (\%) \\
\hline Com enzima e sem L.I. & $142,71 \pm 27,47$ & 182,81 \\
Com enzima e com L.I. & $240,92 \pm 33,12$ & 246,24 \\
Sem enzima e com L.I. & - & - \\
Sem enzima e sem L.I. & - & - \\
\hline
\end{tabular}

De acordo com a Tabela 1, os suportes sem enzima e sem e com o LI não possuem poder de catalisar a reação. Este fato prova que somente a enzima suportada atua como catalisador. Os derivados imobilizados apresentaram rendimento maior que $100 \%$, o que indica que a enzima não sofreu desnaturação após a imobilização e ocorreu um um aumento no rendimento e na atividade enzimática quando adicionado o LI como aditivo, que representa uma melhor distribuição da enzima com o uso do aditivo. Outro teste realizado foi em relação a concentração do LI.

As Figuras 1 e 2 apresentam a atividade de esterificação e o rendimento, respectivamente, obtidos pela imobilização da lipase Candida antarctica $\mathrm{B}$ (Cal B) com o uso de diferentes concentrações de LI como aditivo.

Figura 1 - Atividade de esterificação em diferentes concentrações de líquido iônico

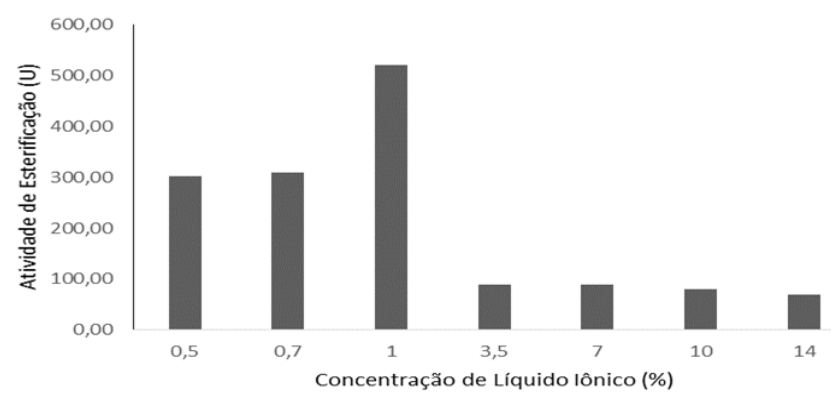

Pode-se observar na Figura 1 que as maiores atividades encontram-se nas menores concentrações de LI, e maior atividade de esterificação foi quando utilizou-se $1 \%$ de LI.

Figura 2 - Rendimento de imobilização em diferentes concentrações de líquido iônico

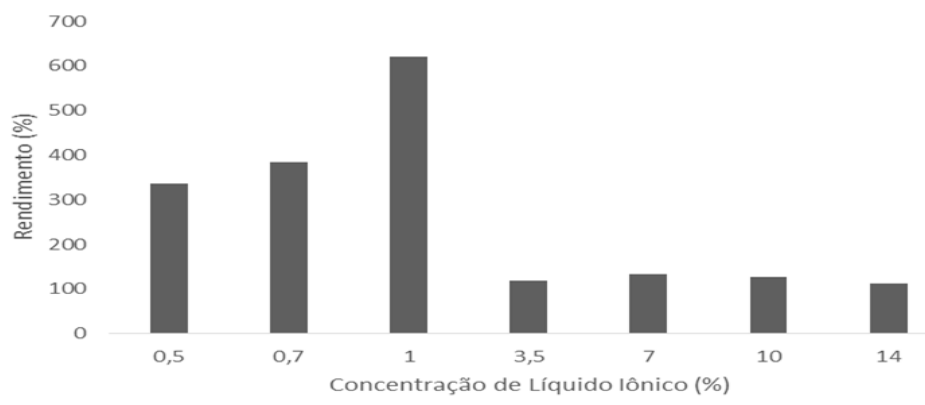


O mesmo comportamento pode ser observado para o rendimento na Figura 2. Os maiores rendimentos de imobilização $(330,380$ e $620 \%$ ) foram nos ensaios com menor concentração de LI $(0,5,0,7$, e $1 \%$ respectivamente). Sendo que na concentração de $1 \%$ de LI o rendimento foi o maior. Em todos os ensaios os rendimentos foram maiores que $100 \%$, indicando que a enzima não sofre desnaturação com o uso de líquido iônico como aditivo.

A presença do LI como aditivo na imobilização pode atuar da mesma maneira que os outros aditivos descritos na literatura, tais como polivinilálcool (PVA), polietilenoglicol (PEG). Durante o processo de imobilização ou síntese do suporte, possivelmente, o aditivo pode estar modificando a hidrofobicidade do microambiente, exercendo influência no nível de umidade dentro do suporte (Mohidem et al., 2011).

$\mathrm{Na}$ literatura diferentes rendimentos de atividades na presença de aditivos são apresentados. Soares et al. (2006) encontraram rendimento de $60 \%$ para a lipase de C. rugosa imobilizada em sílica utilizando PEG-1500 como o aditivo. A lipase de Burkholderia cepacia, imobilizada em xerogel apresentou rendimento de $1526 \%$ com o uso de LI e $43 \%$ sem LI (Souza et al., 2013). Zarcula et al. (2010) também observaram um rendimento da lipase de Pseudômonas fluorescens superior a $100 \%$ em sílica imobilizada pela sol-gel usando um líquido iónico aprótico como aditivo. Barbosa et al (2014) imobilizaram lipase de Burkholderia cepacia em aerogel obtido pela técnica sol-gel, com secagem em meio supercrítico, com o uso de $1 \%$ de líquido iônico prótico da família N-metilmonoetanolamina apresentou aumento no rendimento de imobilização de atividade de 37,27\% (sem LI) para $44,23 \%$ (com LI).

\section{CONCLUSÕES}

Os resultados obtidos no estudo do uso de diferentes concentrações de líquidos iônicos na imobilização da lipase CALB em xerogel demonstram a importância do estudo e os efeitos destes fatores no aumento da atividade e do rendimento da imobilização. As maiores atividades foram encontradas nas menores concentrações estudadas, e a maior atividade (520 $\mathrm{U})$ foi na concentração de $1 \%$ de líquido iônico. A atividade de esterificação variou nas menores concentrações de LI de 300 a 520 U e o rendimento de imobilização de 330 a $620 \%$. Isto demonstra que o LI apresenta efeito positivo na imobilização quando utilizado em baixas concentrações. A melhor concentração encontrada neste estudo foi de $1 \%$ na qual apresentou atividade de $520 \mathrm{U}$ e rendimento de $620 \%$.

\section{REFERÊNCIAS}

ALFAYA, A.; KUBOTA, L. T. A. Utilização de materiais obtidos pelo processo de sol-gel na construção de biossensores. Quim. Nova, v. 25, p. 935-841, 2002.

BARBOSA, A. dos S.; SILVA, M. A. de O.; CARVALHO, N. B.; MATTEDI, S.; IGLESIAS, M. A.; FRICKS, A. T.; LIMA, A. S.; FRANCESCHI, E.; SOARES, C. M. F. Imobilização de lipase por encapsulação em sílica aerogel. Quim. Nova, v. 37, p. 969976, 2014. 
FICANHA, A. M. M. Imobilização de lipase de Candida antarctica B (CALB) pela técnica de sol-gel. Dissertação (Mestrado em Engenharia de Alimentos). Universidade Regional Integrada do Alto Uruguai e das Missões- URI, Erechim, 2014.

HARA, P.; MIKKOLA, J. P.; MURZIN, D. Y.; KANERVA, L. T. Supported ionic liquids in Burkholderia cepacia lipase-catalyzed asymmetric acylation. J. Mol. Catal. B: Enzym., v. 67, p. 129-134, 2010.

HIRATSUKA, R. S.; SANTILLI, C. V.; PULCINELLI, S. H. O Processo Sol-Gel: uma visão físico-química. Quim. Nova, v. 18, n. 2, p. 171-180, 1995.

KAPOOR, M; GUPTA, M. N. Obtaining monoglycerides by esterification of glycerol with palmitic acid using some high activity preparations of Candida antarctica lipase B. Process Biochem., v. 47, p. 503-508, 2012.

KATO, K.; NAKAGAKI, S.; NISHIDA, M.; HIRAO, K. Enzyme encapsulation in silica particles prepared using enzyme-assisted sol-gel reactions in ionic liquids. J. Ceram. Soc. Jpn., v. 119, p. 140-143, 2011.

MOHIDEM N. A.; MAT H. B. Catalytic activity and stability of laccase entrapped in sol-gel silica with additives. J. Sol-Gel Sci. Technol., v. 61, p. 96-103, 2011.

PETERS, M.; ECKSTEIN, M. F.; HARTJEN, G.; SPIESS, A. C.; LEITNER, W.; GREINER, L. Exploring conversion of biphasic catalytic reactions: analytical solution and parameter study. Ind. Eng. Chem. Res., v. 46, p. 7073-7078, 2007.

SOARES, C. M. F.; SANTOS, O. A.; CASTRO, H. F.; MORAES, F. F.; ZANIN, G. M. Characterization of sol-gel encapsulated lipase using tetraethoxysilane as precursor. $J$. Mol. Catal. B: Enzym., v. 39, p.69-76, 2006.

SOUZA, R. L. Emprego de aditivos na imobilização sol-gel de lipases. Dissertação (Mestrado em Engenharia de Processos). Universidade Tiradentes- UNIT, Aracaju, 2012.

SOUZA, R. L.; FARIA, E. L. P.; FIGUEIREDO, R. T.; FREITAS, L. S.; IGLESIAS, M.; MATTEDI, S.; ZANIN, G. M.; SANTOS, O. A. A.; COUTINHO, J. A. P.; LIMA, A. S.; SOARES, C. M. F. Protic ionic liquid as additive on lipase immobilization using silica sol-gel. Enzyme Microb. Technol., v. 52, p. 141-150, 2013.

SOUZA, R. L.; RESENDE, W. C.; BARÃO, C. E.; ZANIN, G. M.; CASTRO, H. F. DE; SANTOS, O. A. A.; FRICKS, A. T.; FIGUEIREDO, R. T.; LIMA, A. S.; SOARES, C. M. F. Influence of the use of Aliquat 336 in the immobilization procedure in sol-gel of lipase from Bacillus sp. ITP-001. J. Mol. Catal. B: Enzym., v. 84, p.152-159, 2012.

ZARCUlA, C.; CORÎCI, L,. CROITORU, R.; URSOIU, A.; PETER, F. Preparation and properties of xerogels obtained by ionic liquid incorporation during the immobilization of lipase by the sol-gel method. J. Mol. Catal. B: Enzym., v. 65, p. 79-86, 2010. 